\title{
EDITORIAL
}

\section{Anti-interleukin 6: first line in rheumatoid arthritis?}

\author{
Luciana Marti • Morton Scheinberg
}

Received: 7 April 2009 / Accepted: 8 April 2009/Published online: 5 May 2009

(C) Clinical Rheumatology 2009

The past decade has witnessed a significant advance in the treatment of rheumatoid arthritis (RA). Agents capable of blocking tumor necrosis factor alpha (TNF $\alpha)$ were the first to be introduced and are still considered first line therapy in patients who had an inadequate response to methotrexate [1]. Two new therapeutic agents directed at antagonizing two previously untargeted pathways have been approved for patients with RA $[2,3]$.

During the past 5 years, a new form of anti-cytokine therapy has been evaluated and a question has been raised: Is there a new world beyond $\mathrm{TNF} \alpha$ blocking agents, B-cell depletion, and T-cell co-stimulation? The latter two therapies will improve the outcomes for RA patients but responses appear only after several weeks, sometimes months, of continuous use.

Tocilizumab (namely MRA), a humanized antiinterleukin 6 receptor monoclonal antibody, was developed for the treatment of RA and certain lymphoproliferative disorders [4]. Tocilizumab has a long plasma half-life, so it can be administered monthly and another preparation is being evaluated for subcutaneous use. A series of studies performed initially in Japan and then throughout the rest of the world have shown that tocilizumab not only improved signs and symptoms in RA patients but also normalized inflammatory markers. More recently, studies have shown that tocilizumab is able to generate adequate responses on the failures of disease-modifying anti-rheumatic drug (DMARDs) and is also able to generate adequate responses

L. Marti $\cdot$ M. Scheinberg $(\square)$

Albert Einstein Research and Education Institute,

Albert Einstein Hospital,

São Paulo, Brazil

e-mail: morton@osite.com.br after inadequate responses to $\mathrm{TNF} \alpha$ antagonists. Tocilizumab is equally good as methotrexate used as monotherapy.

A 5-year follow-up has shown that this medication is effective and has a safety profile to some extent comparable to other biologicals [5-7]. Some adverse events include significant rises in cholesterol and triglyceride levels, elevated serum levels of transaminases, and decreases in white blood cell counts. Significant incidence of infections was not a major issue and tuberculosis was not a problem in patients receiving tocilizumab. Serious clinical manifestations associated with neutropenia or increased lipid levels were not reported.

A number of different observations point to the possibility that tocilizumab, about to be released sometime in 2009, may be the first line medication for patients who need biological and non-biological DMARDs. Approximately $50 \%$ of the patients who show good responses to anti-TNFs during the first year tend to loose these response years late. In our hospital, after 3 years of continuous use, less than $50 \%$ of the patients are still using the medicationeven after titration which reduced the intervals between infusions or doses increased were performed $[8,9]$.

In Brazil and in other countries, switching to a different TNF inhibitor is a common practice, and reports of good responses are being published mostly on an uncontrolled basis. Some studies, however, point to the possibility that switching to another biologic may be more effective $[10,11]$. How will rheumatologists decide which biological to start their RA patients? Usually factors like personal experience safety and patients' choice are involved in the decisionmaking process. Two additional factors, we believe, should also play a role in these circumstances.

Costs are a factor particularly in Third World countries, and it is expected that with various options to start with, market forces should lead a substantial decrease in the 
Table 1 ACR responses (mean percentage) scores four weeks after treatment with Tocilizumab and placebo $(* * \mathrm{p}<0.0001)$

\begin{tabular}{lll}
\hline & Tocilizumab and DMARDS & Placebo and DMARDs \\
\hline ACR 20 & $34.7 \%$ & $13.6 \%$ \\
ACR 50 & $11.0 \% * *$ & $1.8 \% * *$ \\
ACR 70 & $2.9 \%$ & $0 \%$
\end{tabular}

current prices practiced by various industries. Another factor is the time developed to achieve a good response. Depletion of B cells and inhibition of T-cell co-stimulation usually generate adequate responses after a few months. TNF inhibitors showed a quicker response, but are associated with a higher level of discontinuation.

Data derived from two recent published clinical trials (OPTION and TOWARD) show that Tocilizumab and DMARD combination improve RA signs and symptoms as early as two weeks after their use [12] (Tables 1 and 2). In fact, the clinical trial that our group had a chance to be involved was difficult to be completely blinded due to the rapid response induced by Tocilizumab.

Identification of biomarkers that can predict positive responses should certainly help rheumatologists in biologic choice selection. Recently, experiments performed in our laboratory show that anti-TNF $\alpha$ and Tocilizumab after three infusions are associated with significant IL6 levels decrease in the patient's serum; the magnitude of this reduction appears to be more expressive with Tocilizumab therapy (Fig. 1). Studies related to the mechanism on how anti-IL6 reduces IL6 serum levels are underway; one hypothesis being considered is the potent reduction in inflammatory activity after anti-cytokine treatment [13]. Finally, very recent data in experimental arthritis show that IL-6 blockade but not anti TNF inhibition correlates with the degree of Th17 differentiation, a third subset of T cells, shown to be involved with the development of arthritis and induced by IL6 [14, 15].

While parallel trials may help the decision making process, based on extensive scientific grounds, and the rationale developed above it is certainly a possibility that anti-IL6 may become a first line therapy in rheumatoid arthritis in a variety of therapy association and monotherapy.

Table 2 DAS 28 scores before and two weeks after treatment with Tocilizumab and placebo $\left({ }^{*} \mathrm{p}<0.0001\right.$ and $\left.{ }^{* *} \mathrm{p}>0.05\right)$

\begin{tabular}{lll}
\hline & Tocilizumab and DMARDS & Placebo and DMARDs \\
\hline DAS28 & $6.7 / 5.0 *$ & $6.7 / 6.26^{* *}$ \\
\hline
\end{tabular}

IL6 serum reduction after biological therapy

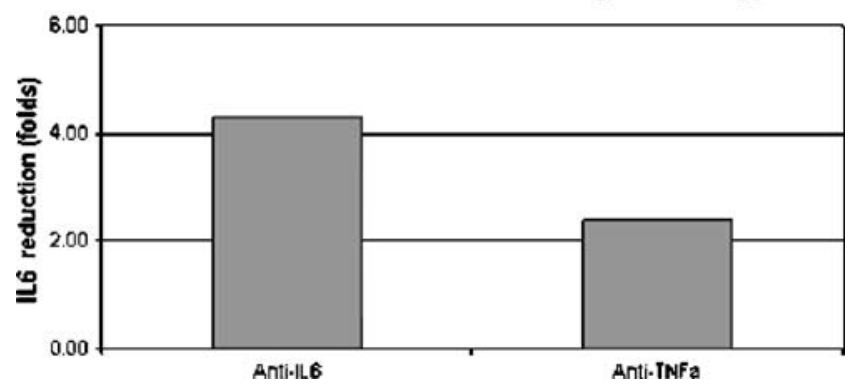

Fig. 1 Anti-IL6 therapy reduces 2 times more the IL6 levels in patient's serum when compared to anti-TNF $\alpha$

Disclosures Doctor Morton Scheinberg was one of the OPTION investigators.

\section{References}

1. Caporali R, Pallavicini FB, Filippini M, Gorla R, Marchesoni A, Favalli EG, Sarzi-Puttini P, Atzeni F, Montecucco C. Treatment of rheumatoid arthritis with anti TNF-alpha agents: a reappraisal. Autoimmun Rev. 2009;8274-80

2. Buch MH, Vital EM, Emery P. Abatacept in the treatment of rheumatoid arthritis Arthritis Res Ther. 2008;10 Suppl 1:S5. Epub 2008. Review

3. Owczarczyk K, Hellmann M, Fliedner G, Röhrs T, Maizus K, Passon D, Hallek M, Ruppert A (2008) Clinical outcome and B cell depletion in patients with rheumatoid arthritis receiving rituximab monotherapy in comparison with patients receiving concomitant methotrexate. Ann Rheum Dis. 67:1648-9

4. Choy E (2008) Inhibiting interleukin-6 in rheumatoid arthritis. Curr Rheumatol Rep. 10:413-7

5. Maini RN, Taylor PC, Szechinski J, Pavelka K, Bröll J, Balint G, Emery P, Raemen F, Petersen J, Smolen J, Thomson D, Kishimoto T, CHARISMA Study Group (2006) Double-blind randomized controlled clinical trial of the interleukin-6 receptor antagonist, tocilizumab, in European patients with rheumatoid arthritis who had an incomplete response to methotrexate. Arthritis Rheum. 54:2817-29

6. Emery P, Keystone E, Tony HP, Cantagrel A, van Vollenhoven R, Sanchez A, Alecock E, Lee J, Kremer J (2008) IL-6 receptor inhibition with tocilizumab improves treatment outcomes in patients with rheumatoid arthritis refractory to anti-tumour necrosis factor biologicals: results from a 24-week multicentre randomised placebo-controlled trial. Ann Rheum Dis 67:1516-23

7. Nishimoto N, Miyasaka N, Yamamoto K, Kawai S, Takeuchi T, Azuma J. Long-term safety and efficacy of tocilizumab, an antiinterleukin-6 receptor monoclonal antibody, in monotherapy, in patients with rheumatoid arthritis (the STREAM study): evidence of safety and efficacy in a 5- year extension study. Ann Rheum Dis. 2008.

8. Agarwal SK, Maier AL, Chibnik LB, Coblyn JS, Fossel A, Lee R, Fanikos J, Fiumara K, Lowry C, Weinblatt ME (2005) Pattern of infliximab utilization in rheumatoid arthritis patients at an academic medical center. Arthritis Rheum. 53:872-8

9. Scheinberg M, Goldenberg J, Feldman DP, Nóbrega JL (2008) Retrospective study evaluating dose standards for infliximab in patients with rheumatoid arthritis at Hospital Israelita Albert Einstein, São Paulo, Brazil. Clin Rheumatol. 27:1049-52

10. Hyrich KL, Lunt M, Watson KD, Symmons DP, Silman AJ (2007) Outcomes after switching from one anti-tumor necrosis factor 
alpha agent to a second anti-tumor necrosis factor alpha agent in patients with rheumatoid arthritis: results from a large UK national cohort study. British Society for Rheumatology Biologics Register. Arthritis Rheum. 56:13-20

11. Finckh A, Ciurea A, Brulhart L, Kyburz D, Möller B, Dehler S, Revaz S, Dudler J, Gabay C (2007) B cell depletion may be more effective than switching to an alternative anti-tumor necrosis factor agent in rheumatoid arthritis patients with inadequate response to anti-tumor necrosis factor agents. Physicians of the Swiss Clinical Quality Management Program for Rheumatoid Arthritis. Arthritis Rheum. 56:1417-23

12. Siri D, Scheinberg M, Kissell K, Genovese M, Smolen J (2008) Tocilizumab is associated with rapid and sustained improvement in RA. Signs and symptoms in inadequate responders in DMARDs. A pooled analysis. J Clin Rheumatol 14:19S
13. Marti L., Golmia R, Golmia APF, Paes AT, Guilhen DD, MoreiraFilho CA, Scheinberg M. Alterations in cytokine profile and dendritic cells subsets in peripheral blood of rheumatoid arthritis patients before and after biologic therapy. New York Academy of Sciences, 2009 (in press)

14. Fujimoto M, Serada S, Mihara M, Uchiyama Y, Yoshida H, Koike N, Nishikawa T, Ripley B, Kimura A, Kishimoto T, Naka T (2008) Interleukin 6 blockade suppresses autoimmune arthritis in mice by the inhibition of inflammatory Th17 responses. Arthritis Rheum 58:3710

15. Iwanami K, Matsumoto I, Tanaka-Watanabe Y, Inoue A, Mihara M, Ohsugi Y, Mamura M, Goto D, Ito S, Tsutsumi A, Kishimoto T, Sumida T (2008) Crucial role of the interleukin-6/interleukincytokine axis in the induction of arthritis by glucose-6-phosphate isomerase. Arthritis Rheum 58:754-763 